\section{REVIEW ARTICLE}

\title{
Sensing, signalling and integrating physical processes during Saccharomyces cerevisiae invasive and filamentous growth
}

\author{
Sean P. Palecek, ${ }^{1}$ Archita S. Parikh ${ }^{2}$ and Stephen J. Kron ${ }^{2,3}$
}

Author for correspondence: Stephen J. Kron. Tel: +1 773834 0250. Fax: +1 7737024394. e-mail: skron@midway.uchicago.edu

\begin{abstract}
${ }^{1}$ Department of Chemical Engineering, University of Wisconsin - Madison, Madison, WI 53706, USA
${ }^{2,3}$ Center for Molecular Oncology ${ }^{2}$ and Department of Molecular Genetics and Cell Biology ${ }^{3}$, The University of Chicago, Chicago, IL 60637, USA
\end{abstract}

Keywords: cell polarity, cell adhesion, pseudohyphal growth, MAPK, cAMP

\section{Introduction}

Simple fungi have evolved sophisticated mechanisms to sense and respond to environmental cues by activating developmental switches that result in coordinated changes in cell physiology, morphology and cell adherence. Critical depletion of nutrients often induces growth arrest to form spores capable of tolerating a wide range of environmental stresses. However, an alternative response is the dimorphic switch to filamentous growth, characterized by branching networks of chains of cells or hyphae to form a mycelium (Gancedo, 2001; Kron \& Gow, 1995). Filamentous growth is considered an important adaptive response that functions analogously to cell motility in allowing a starving fungal colony to forage for nutrients (Lee \& Elion, 1999). Branching filaments permit wider exploration of the environment at a lower biomass (energy) cost than nonfilamentous growth. Cell-cell adherence and highly polarized growth promote invasion of the substrate (Gancedo, 2001). Further, the high surface-to-volume ratio of filaments may facilitate transport of nutrients. The dimorphic switch is essentially modular and may be activated by a wide range of stimuli appropriate to the lifestyle of the fungus. Typically, the dimorphic switch in pathogenic fungi is tuned such that cells elongate or increase cell-cell adherence when exposed to their host (San-Blas et al., 2000; Sanchez-Martinez \& Perez-Martin, 2001). Such regulated dimorphism has been established as an important virulence factor, determining invasion and colonization by pathogenic organisms such as Candida albicans, Magnaporthe grisea (rice blast) and Ustilago maydis (corn smut) (Lengeler et al., 2000; Sanchez-Martinez \& PerezMartin, 2001). Thus the dimorphic switch may prove to be an attractive target for chemical intervention in the prophylaxis and treatment of fungal infections in medicine and agriculture.
In turn, many industrial biochemical processes employ dimorphic yeasts and filamentous fungi to drive production of desired chemical compounds. Fermentation of carbohydrates in fruits, grains and other biomass to ethanol by Saccharomyces cerevisiae is the critical process for a wide range of products from fine wines to gasoline additives (Bothast et al., 1999; Pretorius, 2000). $S$. cerevisiae and other simple fungi are also widely utilized in industrial production of small-molecule metabolites such as citrate and amino acids, bioremediation of toxic contaminants, fermentation of foodstuffs, production of complex organic compounds such as antibiotics, growth of starting material for protein purifications, and expression of heterologous proteins for vaccines, drugs and enzymes (Bennett, 1998; Chartrain et al., 2000; Ostergaard et al., 2000). The manner of organism proliferation, whether in a dispersed or aggregated form, is potentially a limiting factor in production of the desired metabolite(s), utilization of the growth medium and/or separation of cell mass from the soluble product. The classic example of self-clearing of beers at the end of the fermentation by the flocculation and settling of ale yeast underlines that control over cell morphology and/or cell-cell adhesion is a highly desirable characteristic of an industrial micro-organism (Hammond, 1995; Straver et al., 1993). A detailed understanding of how metabolite sensing and signalling leads to changes in physical properties of cells will be critical for cellular engineering approaches to control dimorphism. For example, maintaining cell dispersion is desired during a fermentation to maximize mass transport and reaction rates but inducing flocculation can facilitate separation of the cells from fermentation products. In turn, it should be kept in mind that adhesion and morphology are not the only characteristics that change during the dimorphic transition. Many fungi also switch their patterns of metabolic conversions, gene expression and protein secretion (Viard \& Kuriyama, 

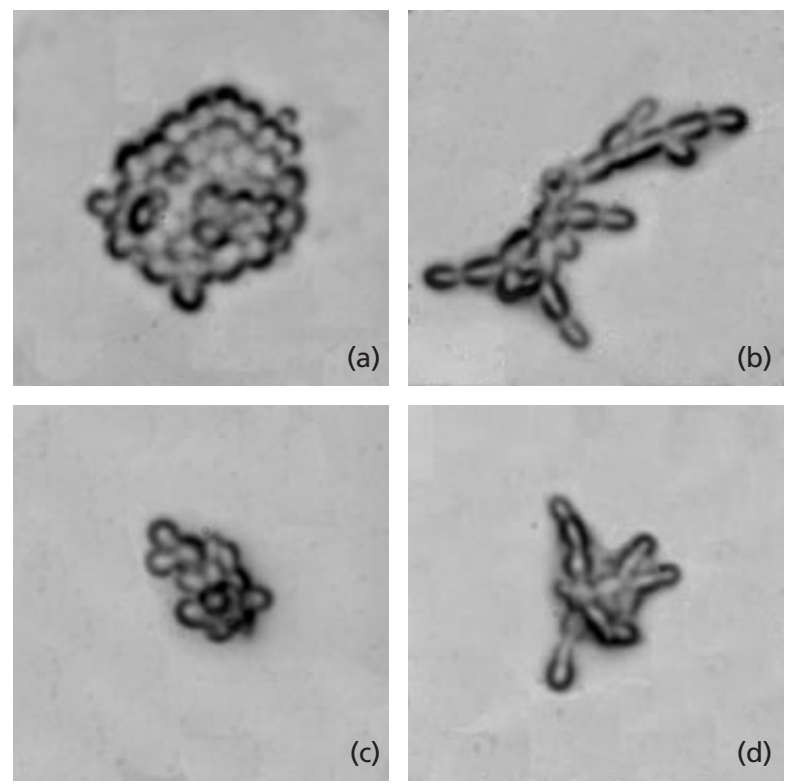

Fig. 1. Diploid S. cerevisiae grows as mounds of independent yeast-form cells on the surface of rich media (a). When starved for nitrogen, these cells switch to pseudohyphal growth, which is characterized by branching chains of cells that spread over and into the agar (b). In comparison, the dimorphic switch induced by nitrogen starvation in haploid $S$. cerevisiae leads to limited changes in cell morphology and the formation of short filaments (c). However, mutants lacking SIR4 and expressing both mating loci display the nearly full expression of the filamentous phenotype in haploid strains (d).

1997; Wartmann \& Kunze, 2000). Yeast form and filamentous cells also differ in their expression and accumulation of undesirable cell constituents and the ease with which cells can be disrupted or fractionated (Gibbs et al., 2000; Khale \& Deshpande, 1992; San-Blas, 1993).

Clearly, active control of dimorphic growth can take advantage of these circuits to increase uptake of reactants or secretion of products in industrial applications or to potentially provide new strategies to combat colonization or invasion by dimorphic fungi. As a first approach to molecular dissection of fungal dimorphism, we and others have turned to laboratory strains of the budding yeast $S$. cerevisiae and have examined the molecular and genetic determinants of pseudohyphal growth. In its starvation-induced filamentous differentiation response, $S$. cerevisiae switches from growth as mounds of independent yeast-form cells on the surface of agar media (Fig. 1a) to branching chains of cells that spread over and into the agar (Fig. 1b). Yeast-form growth of diploid S. cerevisiae is characterized by ovoidshaped cells, a $G_{1}$ cell cycle delay, asymmetric cell division, bipolar bud site selection and cell separation following mitosis. Filamentous or pseudohyphal growth in diploid S. cerevisiae cells is characterized by cell elongation, a mitotic delay, symmetric cell division, unipolar budding and persistent physical attachment of mother and daughter cells (Gimeno et al., 1992; Kron et al., 1994). In comparison to diploid cells, dimorphic switching in haploid S. cerevisiae is more subtle, leading to increased cell-cell adhesion but only limited changes in cell morphology (Fig. 1c). However, mutations in genes regulating mating type permit the nearly full expression of the filamentous phenotype in haploid strains (Fig. 1d). Since the discovery of the $S$. cerevisiae pseudohyphal differentiation response to nitrogen starvation a decade ago (Gimeno et al., 1992), this phenomenon has been characterized extensively (Gancedo, 2001; Lengeler et al., 2000; Pan et al., 2000). Other signals such as poorly utilized carbon sources also induce filamentous growth. Much of the signal transduction mechanism has been mapped, from the nutrient receptors to transcription factors. Finally, molecular effectors of the physical components of pseudohyphal growth have been uncovered. This review details the current state of knowledge of environmental sensing, signal transduction and the physical mechanisms of filamentous growth in S. cerevisiae.

\section{Environmental sensing mechanisms}

\section{Nitrogen starvation}

Laboratory culture conditions for S. cerevisiae, whether in liquid media or on solid agar, have been developed to optimize cell growth. Typically, these conditions initially provide an excess of all necessary nutrients. Cells respond to such rich media containing abundant nitrogen sources and a fermentable carbon source by adopting a dispersed yeast form and growing rapidly, with the fermentation mixed actively by evolved carbon dioxide and/or mechanical agitation. A similar pattern is observed during the early stages of fermentation of beer worts and wine musts (Kleyn \& Hough, 1971). However, once depletion of the media results in sufficiently low nutrient concentrations to limit cell growth, yeast undergo divergent responses that reflect the nutrients available in the media and the cell's microenvironment. At the diauxic shift, when fermentable carbon sources are exhausted, cells transiently arrest and then reprogram their metabolic patterns to metabolize ethanol and continue slow, vegetative growth (Russell et al., 1993). Coincident with this switch, cells may become flocculent or change morphology. Later in the fermentation, when confronted by oxygen depletion, critical deprivation of a complex nutrient or complete carbon or nitrogen source starvation, haploid and diploid cells arrest in stationary phase, a $G_{0}$ exit from the cell cycle. During conditions of moderate nitrogen starvation and when nonfermentable carbon sources and oxygen are available, diploid cells can enter meiosis and perform sporulation before arresting. However, during moderate nitrogen limitation in the presence of adequate fermentable carbon source, a situation that wild yeasts may experience when colonizing ripened fruits, yeast continue slow vegetative growth and perform a dimorphic switch (Gimeno et al., 1992). Diploid cells switch from yeast form to invasive and/or filamentous growth while haploid cells adopt an invasive 
growth phenotype (Gimeno et al., 1992), forming a film that spreads over and into the solid substrate.

The high-affinity ammonium permease Mep2 is one receptor that cells use to detect nitrogen compounds. Strains lacking Mep2 can acquire ammonium and grow at normal rates but do not form filaments in response to ammonium limitation (Lorenz \& Heitman, 1998b). These results suggest that Mep2 senses ammonium starvation and produces a signal leading to filamentous differentiation. Mep1, a low-affinity permease, may also play a role in nitrogen sensing since deletion of MEP1 allows downstream activation of filament formation in a strain lacking Mep2 (Lorenz \& Heitman, 1998a). Perhaps Mep1 and Mep2 signals are integrated to provide a more accurate measure of nitrogen availability.

Amino acid concentrations also affect filamentous growth, either by providing a nitrogen source or via an independent signalling mechanism. For example, mutations in the SSY1 amino acid permease or the PTR3 peptide permease regulator induce elongation and enhance invasive growth in haploid strains (Klasson et al., 1999). Mutations in SHR3, which is involved in processing amino acid permeases, also enhance filamentous growth (Gimeno et al., 1992). The amino acid sensor may be intracellular. The 'charge' of the glutamine tRNA isoform tRNA-CUG is a candidate as a mutation in this tRNA results in pseudohyphal growth and sporulation at high nitrogen concentrations (Murray et al., 1998). Similarly, components of nitrogen catabolism also play a role in filamentous growth and may be involved directly or indirectly in sensing nitrogen concentrations and transmitting filamentous growth signals. In the nitrogen regulation pathway, the regulator $M K S 1$ acts upstream of the transcription factors URE2 and GLN3 to promote transcription of DAL5, an allantoate and ureidosuccinate permease. Overproduction or depletion of Mks1 reduces filamentation on low nitrogen media (Edskes et al., 1999). Deletion of URE2 and GLN3 also results in the loss of filament formation in response to low nitrogen (Lorenz \& Heitman, 1998b). A key issue in understanding nitrogen regulation of filamentous growth will involve differentiating nitrogen uptake and assimilation versus nitrogen sensing and signalling. Separate pathways might exist, or regulation of each might be integrated. A more in-depth study of this process with new genetic tools will be required to answer this question.

\section{Carbon source regulation}

Another receptor necessary for pseudohyphal differentiation is Gpr1, a cell surface G-protein-coupled receptor that binds to the heterotrimeric GTP-binding protein alpha subunit Gpa2 (Xue et al., 1998; Yun et al., 1998). Strains lacking Gpr1 are defective in both diploid filament formation and haploid invasive growth (Lorenz et al., 2000b; Tamaki et al., 2000). Nitrogen starvation induces GPR1 transcription (Xue et al., 1998) but the primary function of Gpr1 appears to be glucose sensing. Gpr1 binds glucose with a very low affinity and activates cAMP signalling in a Gpa2-dependent manner (Lorenz et al., 2000b; Rolland et al., 2000; Yun et al., 1998). Gpr1 may monitor glucose levels necessary for filamentous growth, or may integrate glucose and nitrogen signals in the pseudohyphal pathway.

A role for glucose transporters during filamentous growth has not been identified. However, mutations in mannose utilization and protein glycosylation pathways activate a mitogen activated protein kinase (MAPK) signalling pathway used in invasive and filamentous growth (Cullen et al., 2000). Also, metabolic enzymes may directly or indirectly regulate filamentous phenotypes. For example, a mutation in the NADP-linked glutamate dehydrogenase $G D H 3$ induces elongation and polarized budding in haploid cells (Wilkinson et al., 1996). In addition, mutations in genes encoding phosphoglucose isomerase (PGI1), 6-phosphogluconate dehydrogenase (GND1) and alcohol dehydrogenase (ADH1) constitutively activate invasive growth in haploid strains and enhance pseudohyphal development in nitrogen-deprived diploids (Palecek et al., 2000).

One aspect of carbon source regulation of haploid invasive growth requires Snf1-mediated gene repression (Carlson, 1999; Gancedo, 1998). In the absence of glucose, cells elongate, the budding pattern polarizes and cells invade agar (Cullen \& Sprague, 2000). Snf1 is required for expression of glucose-repressed genes responsible for invasive growth in the absence of glucose, perhaps via the transcription factor Sip4 (Cullen \& Sprague, 2000). It remains to be determined which genes are regulated by Snf1 and which of these may contribute to cell invasion.

Starch degradation also appears to be linked to pseudohyphal development. Transcription of the glycoamylaseencoding genes STA1-3 is repressed by STA10, but restored by overexpression of MSN1 (Lambrechts et al., 1996). Interestingly, MSN1 overexpression also induces filamentous and invasive growth. Therefore, STA1-3 may be coregulated with effectors of filamentous growth (Gagiano et al., 1999), possibly suggesting an evolutionary development of invasive growth based on carbon metabolism. These recent studies demonstrate that carbon source metabolism is as important as nitrogen concentrations in determining cell growth states. In fact, the two signals likely act in concert to determine cell morphology.

Taken together, studies on how nitrogen and carbon starvation induce invasive and filamentous growth suggest multiple regulatory points in each pathway, and crosstalk between the pathways. Changing any single component may rearrange metabolic fluxes in a manner that is difficult to predict. New approaches to metabolic systems modelling and design (Christensen \& Nielsen, 2000; Schilling et al., 1999) will likely contribute to identifying the particular components that signal invasion and filamentation, and offer predictions for how to regulate intracellular activities of those components. 


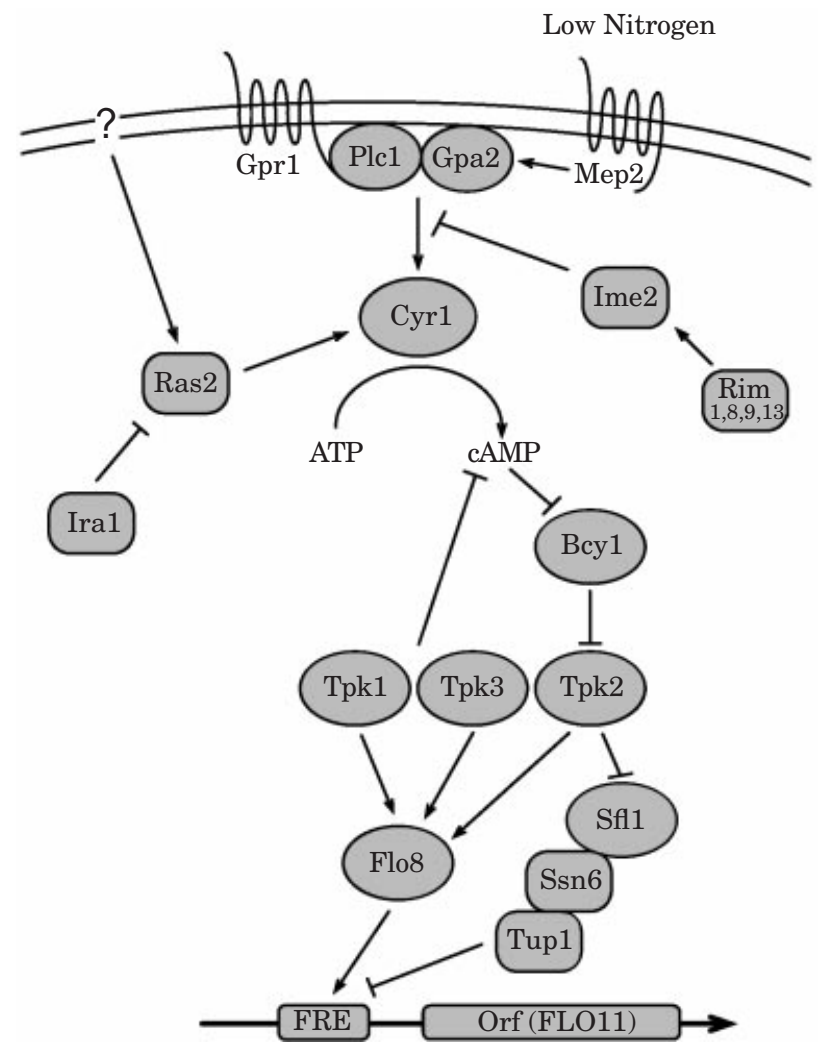

Fig. 2. CAMP-PKA pathway regulates filamentous growth in $S$. cerevisiae. Glucose and nitrogen sensors stimulate cAMP production and activate PKA signalling. PKA activates transcription of genes regulated by filamentous response elements (FREs).

\section{Signal transduction during filamentous growth}

The signalling pathways responsible for regulating filamentous growth are quite complex, involving several parallel pathways encompassing crosstalk and feedback. Yet, considerably more is known about the signal transduction pathways than the sensors and effectors of pseudohyphal differentiation. The two best characterized pathways regulating filament formation are the cAMP-dependent protein kinase (Protein Kinase A, PKA) and STE MAPK cascades (reviewed by BorgesWalmsley \& Walmsley, 2000; D'Souza \& Heitman, 2001; Lengeler et al., 2000; Pan et al., 2000; Posas et al., 1998).

\section{PKA-stimulated filamentous growth}

In yeast vegetative growth, activation of Ras 2 stimulates the adenylate cyclase Cyr1 and elevates intracellular cAMP concentrations (see Fig. 2). cAMP activates the yeast PKAs, each of which consists of one of three catalytic subunits, Tpk1-3, that form a complex with a single cAMP-binding regulatory subunit, Bcy1. Ras2 is required for pseudohyphal growth and a dominant active $R A S 2^{\text {Val19 }}$ allele induces filamentous growth even in the absence of nitrogen starvation (Gimeno et al.,
1992). The role of PKA during filamentous growth is more complex. Mutations in BCY1 activate PKA and enhance filamentous growth at both low and high nitrogen concentrations (Pan \& Heitman, 1999). Tpk2 is required for filamentous growth but Tpk1 and Tpk3 are not (Robertson \& Fink, 1998; Robertson et al., 2000). In fact, mutations in TPK 2 repress filamentation while mutations in TPK1 and TPK3 enhance filamentous growth (Pan \& Heitman, 1999). Furthermore, mutations in TPK 2 are epistatic to mutations in TPK1 and TPK3, suggesting that Tpk1 and Tpk3 exert negative feedback on cAMP production, preventing activation of Tpk2. Interestingly, overexpression of the Yak1 kinase, an antagonist of the cAMP-PKA pathway, enhances pseudohyphal growth in response to nitrogen starvation (Zhang et al., 2001). In the absence of glucose, Yak1 localizes to the nucleus where it phosphorylates Pop2, a transcriptional regulator of glucose-repressed genes (Moriya et al., 2001). Thus Yak1 may be a key link between glucose sensing and invasive or filamentous growth.

The Gpr1 receptor and Gpa2 G-protein also activate adenylate cyclase and PKA but do not appear to function upstream of Ras2. Incubation with cAMP or deletion of the PDE2 phosphodiesterase each restores filamentous growth to a gpa2 $\Delta / g$ pa2 $\Delta$ strain (Kubler et al., 1997; Lorenz \& Heitman, 1997). BCY1 mutations also enhance filamentous growth in GPA2 and GPR1 mutant strains (Pan \& Heitman, 1999). A surprising role for the Plc1 phospholipase $\mathrm{C}$ may be to regulate activation of Gpa2 by Gpr1. PLC1 deletion, which prevents Gpr1 from associating with Gpa2, also inhibits filament formation. Plc1 activity may have a role in coupling carbon and nitrogen signalling at the sensor level (Ansari et al., 1999).

\section{MAPK-stimulated filamentous growth}

In addition to stimulating PKA activity, Ras2 also affects filamentous growth via a MAPK signalling cascade (Mosch et al., 1999) (Fig. 3). The filamentous MAPK cascade contains the protein kinases Ste20 (MAPKKKK), Ste11 (MAPKKK), Ste7 (MAPKK), Kss1 (MAPK) and the transcription factor Ste12 (Posas et al., 1998).

Kss1 can both activate and inhibit filamentous growth. Unphosphorylated Kss1 binds to and prevents Ste12 from activating transcription of genes contributing to pseudohyphal growth. Conversely, Ste7 phosphorylation of Kss1 relieves its inhibition of Ste12 in addition to activating Kss1 (Bardwell et al., 1998; Cook et al., 1997), which further increases transcription through Ste12. Two additional proteins, Dig1 and Dig2, are required for Kss1-mediated repression of Ste12. A $\operatorname{dig} 1 \Delta \operatorname{dig} 2 \Delta$ double mutant strain invades constitutively (Cook et al., 1997). Interestingly, KSS1 deletion does not affect invasive growth in this mutant, perhaps since the repression and activation functions of Kss1 are both abrogated. This mutation does provide a useful means for shielding transcriptional events from signalling 


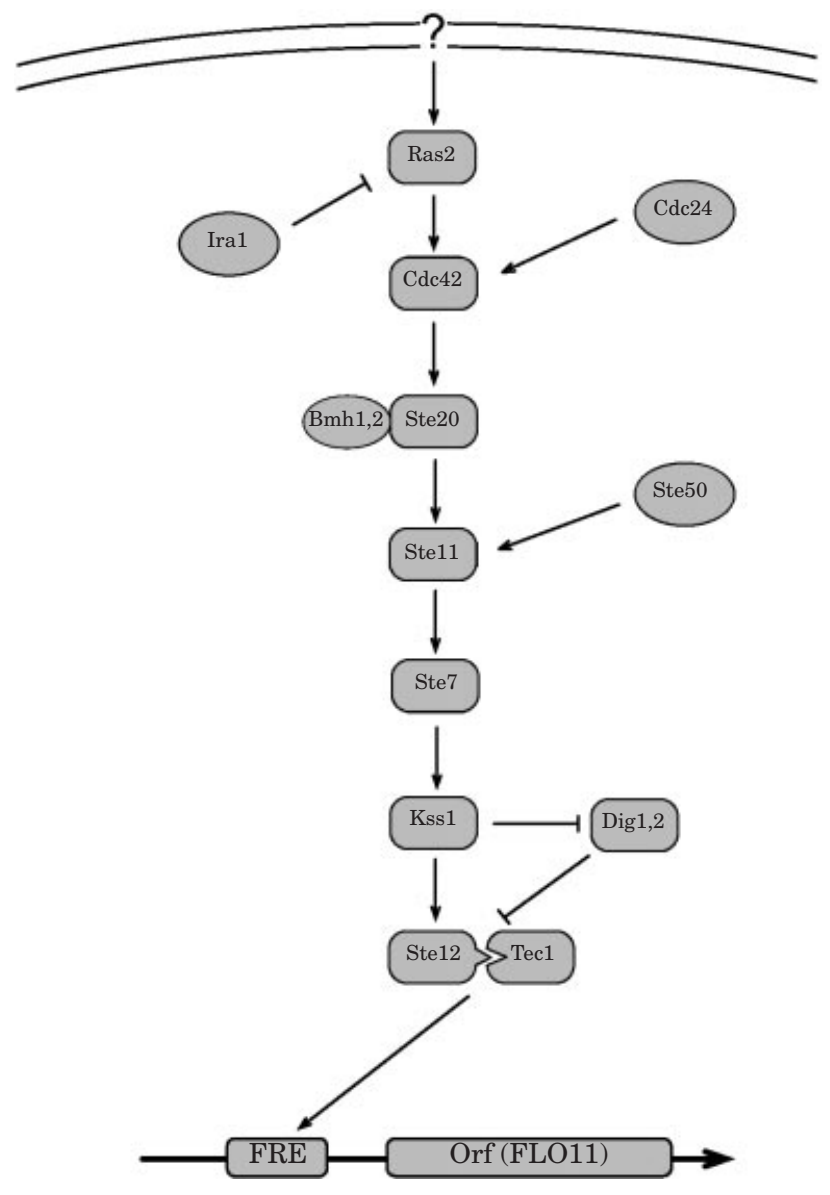

Fig. 3. MAPK pathway regulates filamentous growth in $S$. cerevisiae. External signals activate Ras2 and the MAPK signalling cascade to induce transcription of genes regulated by filamentous response elements (FREs).

through the MAPK filamentous growth pathway since the mechanisms required for filamentous growth are still in place, but elements downstream of Kss1 are isolated from any upstream activation or repression. The activation-repression system of Kss1 may provide a mechanism for cells to isolate invasive and pseudohyphal growth signals through the MAPK cascade from pheromone and osmotic shock signals through the same pathway. Mating pheromone activates Kss1, but Fus3 blocks invasive growth initiation via this activation (Sabbagh et al., 2001). Interestingly, transcription and activity of the Ty1 retrotransposon is also regulated reciprocally by the invasive growth and mating pathways. Kss1 activates invasive growth and Ty1 transposition through Ste12 and Tec1 (Morillon et al., 2000) while the Fus3 MAPK inhibits both invasive growth and Ty1 transposition (Conte \& Curcio, 2000).

The PAK kinase Ste20 and the MEK kinase Ste11 appear to integrate multiple signals to modulate activation of the filamentous MAPK pathway. Dominant active alleles of the Rac/Rho GTPase CDC42 induce constitutive pseudohyphal differentiation while dominant negative alleles of CDC42 block filamentation in re- sponse to the activated RAS2 ${ }^{\text {Val19 }}$ allele (Mosch et al., 1996). When bound to GTP, Cdc42 binds and activates Ste20, and requires Ste20 to induce filamentous growth (Peter et al., 1996). Several CDC42 mutations block elongation in response to low nitrogen but do not affect cell morphology in rich media, placing CDC42 in the nitrogen signalling pathway (Mosch et al., 2001). Twohybrid analysis of $c d c 42$ mutants suggests that Gic1, Gic2 and the PAK-like protein kinase Skm1, in addition to Ste20, may function as effectors of Cdc42 in the pseudohyphal and invasive pathways. The yeast 14-3-3 proteins Bmh1 and Bmh2 also associate with Ste20 and are essential for pseudohyphal growth in strains carrying activated alleles of CDC42 or RAS2 (Roberts et al., 1997). Ste 50 binds to Ste11 and is required for activation during filamentous signalling and other responses (Jansen et al., 2001).

Cell cycle signals may also impinge on activation of the MAPK pathway at the level of Ste20. Overexpression of the $G_{1}$ cyclins CLN1 and CLN2 enhances filamentous and invasive growth, represses pheromone signalling, and results in phosphorylation of Ste20 (Fujita et al., 1999; Madhani et al., 1999; Oehlen \& Cross, 1998). However, another study demonstrated that $\mathrm{Cln} 1$ and $\mathrm{Cln} 2$ act in parallel to the STE MAPK pathway during filamentous growth (Loeb et al., 1999). Hsl7, a negative regulator of the Swe1 protein kinase, apparently also binds to Ste20 and Cdc42 (Fujita et al., 1999). HSL7 deletion induces cell elongation and filament formation in rich medium, but this phenotype is diminished by a STE20 deletion.

\section{Transcriptional pathways connecting signalling to gene expression in filamentous growth}

The transcription factor Tec1 is required for filamentous growth stimulated by the MAPK cascade but not by activated PKA (Gavrias et al., 1996; Pan \& Heitman, 1999). Both Ste12 and Tec1 bind to filamentous and invasion response elements (FREs), including an FRE in the TEC1 promoter (Madhani et al., 1997). Therefore, positive feedback appears to be present in filamentous signalling at the transcriptional level and may serve to amplify the filamentous growth signal. The transcription factor Flo8 is also required for pseudohyphal and invasive growth (Liu et al., 1996) by regulating expression of the flocculins FLO1, 9 and 11 (Kobayashi et al., 1999) as well as STA1-3 (Gagiano et al., 1999). Flo8 appears to regulate invasive and filamentous growth in a pathway independent from Ste12 but acts downstream of the cAMP-PKA pathway (Rupp et al., 1999).

Phd1 is a transcription factor that induces filamentous differentiation when overexpressed (Gimeno \& Fink, 1994). PHD1 transcription is induced by mating pheromones and nitrogen starvation, demonstrating another link between the mating and filamentous growth pathways (Erdman et al., 1998). In combination with a STE12 mutation, deletion of PHD1 completely suppresses diploid filamentous growth, suggesting that it functions in a parallel pathway (Lo et al., 1997). The 
forkhead transcription factors Fkh1 and Fkh2 also regulate filament formation and invasive growth. Deletion of both FKH1 and FKH2 induces filamentous growth while a single deletion of either forkhead gene has no effect (Hollenhorst et al., 2000). Fkh1 and Fkh2 regulate transcription of CLB2 and other genes involved in mitosis that antagonize filamentous growth, further demonstrating the link between the cell cycle and pseudohyphal growth (Zhu et al., 2000). The forkhead factors are required for proper expression of the transcription factors Swi5 and Ace2, antagonists of filamentous growth that direct expression of proteins involved in cell cycle exit and cytokinesis. The transcription factor Ash1 also functions late in the cell cycle, but its activity is instead necessary for pseudohyphal growth, perhaps to regulate interactions between mother and daughter cells (Chandarlapaty \& Errede, 1998).

Transcriptional repression also regulates the activity of genes influencing pseudohyphal growth. For example, the transcriptional repressor Sfl1 interacts with the Tpk2 subunit of PKA, but not the Tpk1 or Tpk3 subunits (Robertson \& Fink, 1998). Sfl1 also acts with the Ssn6-Tup1 general corepressor complex to regulate transcription of genes including FLO11, suggesting that Sfl1 mediates relief of transcriptional repression by cAMP signalling (Conlan \& Tzamarias, 2001). Inactivation of Sok2 enhances invasion and filament formation, and Sok 2 overexpression represses these processes. Sok2 appears to act downstream of the PKA subunits (Ward et al., 1995) but also in a separate, PKAindependent pathway (Pan \& Heitman, 2000). Genome array analysis of a sok $2 \Delta / \operatorname{sok} 2 \Delta$ strain reveals that the transcription factors PHD1, ASH1 and SWI5 are normally repressed by Sok2 (Pan \& Heitman, 2000). However, transcription of these genes is not affected by TPK2 deletion.

The RNA polymerase II complex also regulates invasive and filamentous growth, perhaps by altering expression of effectors and repressors of these processes. Overexpression of the RNA polymerase subunit RPB7 causes cell elongation and filament formation (Khazak et al., 1995). Also, mutations in other components of the RNA polymerase II complex - Ssn3, Ssn8, Srb8, Cse2 and Med1 - constitutively activate invasive growth in haploids (Palecek et al., 2000).

\section{Other pathways involved in filamentous differentiation}

A recent observation has been that stress-induced signalling has an important role in filamentous growth. In addition to nitrogen and carbon starvation, oxygen limitation may also affect dimorphic switching in both haploids and diploids (Wright et al., 1993). Osmotic shock transduced via the Sho1 receptor may also enhance filamentous growth (O'Rourke \& Herskowitz, 1998). Additionally, various alcohols also generate morphological changes in cells. Ethanol enhances diploid strain filamentation, and other alcohols including 1- butanol, isoamyl alcohol and n-amyl alcohol stimulate filamentous growth in haploids growing in glucosecontaining liquid medium (Lorenz et al., 2000a). Perhaps a shared metabolic intermediate is responsible for generating a filamentous growth signal or the induction of filamentous growth may reflect that the alcohols serve as cellular 'irritants'. Skn7, a transcription factor that mediates oxidative stress responses downstream of PKA, is required for filament formation in response to nitrogen starvation (Lorenz et al., 2000b). Mutations in SKN7 can also induce constitutive invasive growth in haploids (Palecek et al., 2000). In addition, the stress-responsive transcriptional repressor Xbp1 represses CLB2 expression to induce cell elongation and filament formation in response to nitrogen starvation (Miled et al., 2001). Ras2 activity also decreases the activity of the stressresponsive transcription factors Msn2 and Msn4. This suppressed stress response has been suggested to be responsible for inducing invasive growth (Stanhill et al., 1999).

The unfolded protein response pathway transcription factor Hac1 plays an interesting role in pseudohyphal differentiation. Hac1 activates transcription of endoplasmic-reticulum-resident chaperones and is also stimulated by the unfolded protein response, a signal generated by unfolded proteins in the ER lumen. Deletion of HAC1 derepresses filamentous growth while overexpression of HAC1 represses pseudohyphae formation (Schroder et al., 2000). HAC1 mRNA is cleaved by Ire1 and spliced by tRNA ligase. High nitrogen concentrations stimulate this splicing, which ceases during nitrogen starvation. Therefore, nitrogen starvation may at least partially stimulate filamentous growth by slowing protein translation rates, inactivating the unfolded protein response, and inhibiting HAC1 splicing (Schroder et al., 2000).

Other yeast developmental responses, such as entering the sporulation pathway, also respond to environmental stresses. In general, sporulation occurs under conditions of nitrogen and carbon starvation while pseudohyphal differentiation is induced in nitrogen-poor but carbonrich environments. This switch may be mediated by Gpa2, which, when overexpressed, reduces sporulation but enhances filamentous growth (Donzeau \& Bandlow, 1999; Lorenz \& Heitman, 1997). Gpa2 appears to direct cells toward pseudohyphal growth rather than sporulation by directly interacting with the Ime2 kinase (Donzeau \& Bandlow, 1999). In turn, overexpression of Ime2 inhibits pseudohyphal growth but enhances sporulation in the presence of glucose and nitrogen while RIM1, 8, 9 and 13 mutations reduce IME2 activity and switch cells from meiotic division to filamentous growth (Li \& Mitchell, 1997). Mutations in BIR1, a gene homologous to inhibitor of apoptosis (IAP) proteins in vertebrates, also enhance pseudohyphal growth but block sporulation during carbon source deprivation (Uren et al., 1999).

Not surprisingly, genes linking nutrient regulation to cell growth and division also affect filament formation. The abundance and activity of the $G_{1}$ cyclin $C \ln 3$ has 
(a)

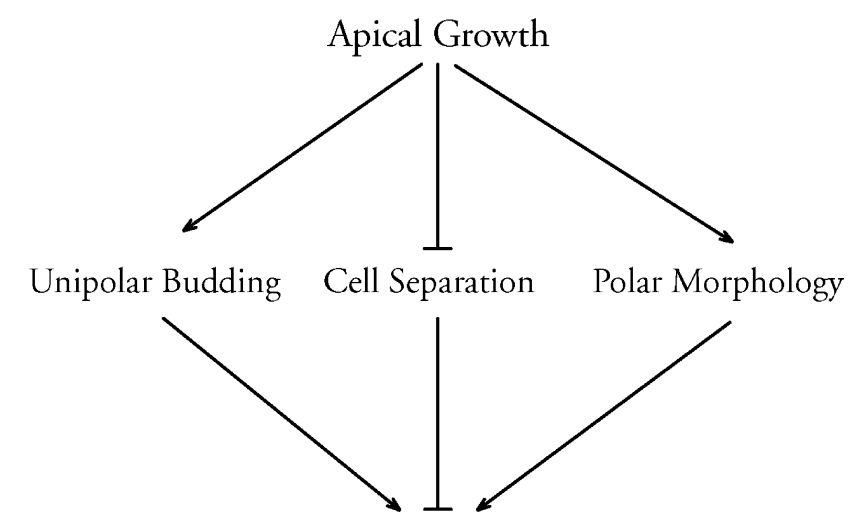

Filamentous Growth (b)

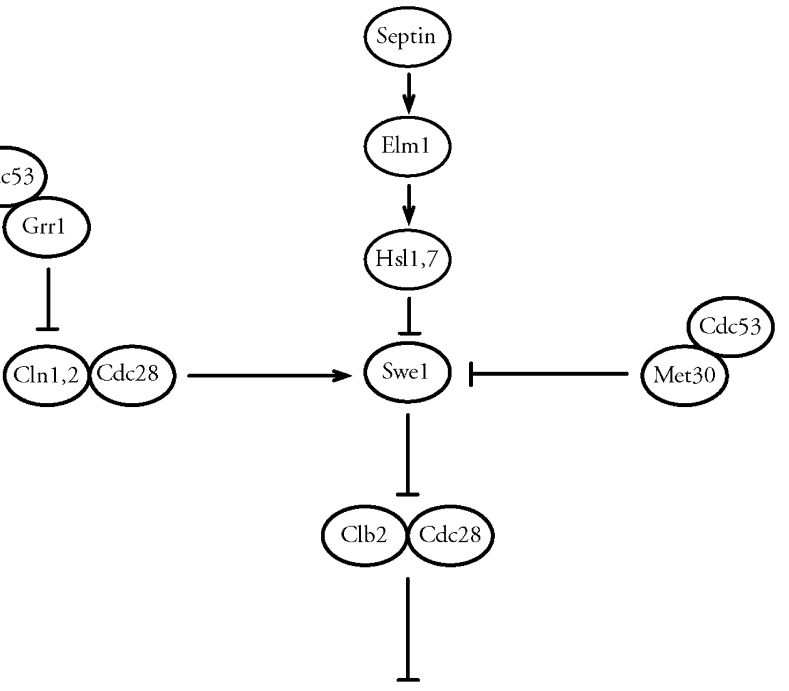

Apical Growth/ Polar Morphology

(c)

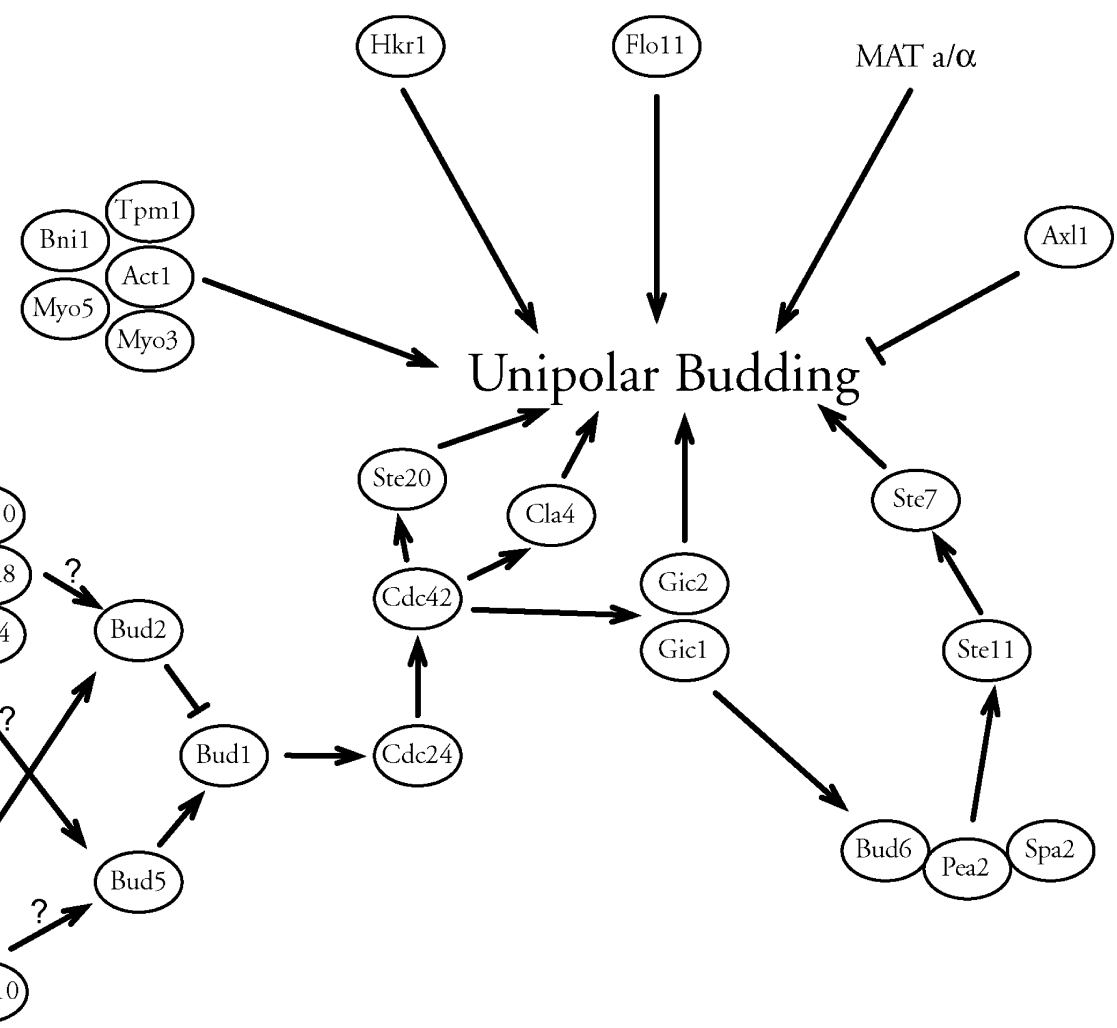

Fig. 4. Regulation of physical responses during filamentous growth. Cell adhesion, elongation and polarized bud site selection contribute to filamentous growth (a). Swe1 inhibits Clb2-Cdc28 activity to regulate apical growth and cell shape (b). Several different pathways affect invasive growth via bud site selection (c).

multiple connections to cell-size control and nutrient sensing during vegetative growth - Cln3 accumulates when cells have sufficient nutrients to continue growth. Deletion of CLN3 confers enhanced pseudohyphal growth (Loeb et al., 1999), suggesting that Cln3 abundance may carry part of the nitrogen starvation signal. Overexpression of WHI2, a gene required for cell cycle arrest upon carbon source depletion, stimulates filamentous growth (Radcliffe et al., 1997). However, WHI2 is not required for pseudohyphal growth and is partially blocked by mutations in the STE MAPK pathway. Deletion of the Whi3 RNA-binding protein abrogates filamentous growth, leading to small round cells on nitrogen starvation media (Mosch \& Fink, 1997). 
Table 1. Cell-cell adhesion

\begin{tabular}{|c|c|c|}
\hline $\begin{array}{l}\text { Gene } \\
\text { name }\end{array}$ & Protein function & Role in invasion (mutant phenotype) \\
\hline ACE2 & $\begin{array}{l}\text { Transcription factor; } \\
\text { DNA-binding protein }\end{array}$ & $\begin{array}{l}\text { Regulates CTS1 transcription; involved in regulation of } \mathrm{G}_{1} \text { genes including ASH1, CDC6, } \\
\text { EGT2, PCL2, PCL9, RME1 and SIC1; mutation enhances invasive and filamentous } \\
\text { growth }\end{array}$ \\
\hline ASH1 & $\begin{array}{l}\text { Transcription factor; } \\
\text { repressor }\end{array}$ & Required for transcription of FLO11; mutant defective in filamentous growth \\
\hline CTS1 & Endochitinase & $\begin{array}{l}\text { Required for separation of mother and daughter cells following cytokinesis; diploid mutant } \\
\text { displays enhanced filamentous growth }\end{array}$ \\
\hline EGT2 & Endoglucanase & $\begin{array}{l}\text { Involved in separation of mother and daughter cells following cytokinesis; mutant diploid } \\
\text { displays enhanced filamentous growth }\end{array}$ \\
\hline FLO8 & Transcription factor & $\begin{array}{l}\text { Regulates FLO11 transcription downstream of the PKA pathway; mutants defective in } \\
\text { invasive and filamentous growth }\end{array}$ \\
\hline FLO11 & Cell-surface flocculin & $\begin{array}{l}\text { Promotes agar invasion and cell adhesion; mutants defective in invasive and filamentous } \\
\text { growth }\end{array}$ \\
\hline STE12 & Transcription factor & $\begin{array}{l}\text { Regulates FLO11 transcription downstream of the MAPK pathway; mutants defective in } \\
\text { invasive and filamentous growth }\end{array}$ \\
\hline SWI5 & $\begin{array}{l}\text { Transcription factor; } \\
\text { DNA-binding protein }\end{array}$ & $\begin{array}{l}\text { Involved in regulation of } \mathrm{G}_{1} \text { genes including ASH1, CDC6, EGT2, PCL2, PCL9, RME1 } \\
\text { and SIC1; mutant diploid displays enhanced filamentous growth }\end{array}$ \\
\hline TEC1 & $\begin{array}{l}\text { Transcription factor; } \\
\text { DNA-binding protein }\end{array}$ & $\begin{array}{l}\text { Regulates FLO11 transcription downstream of the MAPK pathway; mutant diploid defective } \\
\text { in filamentous growth }\end{array}$ \\
\hline
\end{tabular}

Invasive growth is inversely proportional to ploidy for haploid to tetraploid cells (Galitski et al., 1999), suggesting a gene-dose-dependent regulation of invasive growth or a connection to cell size, which increases proportionally to ploidy. Similarly, deletion of SIR 2 or SIR4 results in a loss of silencing of silent mating type cassettes, and expression of diploid specific genes in haploid cells. Consequently, sir 2 and sir4 haploid mutants undergo polarized bud site selection and haploid invasive growth (Palecek et al., 2000). These mutants also exhibit moderate pseudohyphal growth (Fig. 1), suggesting that mating type, in addition to ploidy, plays a role in filamentous growth.

\section{Physical events during invasive and filamentous growth}

The signalling pathways governing formation of filamentous networks of yeast cells ultimately affect physical properties of individual cells, such as adhesion, budding polarity and shape. How each of the pathways described above regulates each physical process remains somewhat of a mystery, but we are beginning to understand how these processes contribute to filamentous and invasive growth (see Fig. 4).

\section{Adhesion and cytokinesis}

Cell attachment is critical during both invasive and filamentous growth. Without sufficient attachment, filaments may not possess the mechanical integrity to penetrate their surrounding matrix. Attachment can be regulated in at least two different ways: persistence of adhesion following cell separation or incomplete mother-daughter separation. Genes regulating each of these mechanisms are listed in Table 1 . In S. cerevisiae, cell-cell adhesion that can be detected as formation of multicellular aggregates is mediated in part by flocculins, a family of highly glycosylated glycosylphosphatidylinositol-anchored proteins. Flo11 appears to be the most important flocculin during invasive and filamentous growth. Deletion of FLO11 eliminates agar invasion as well as filament formation and cells grow in disorganized piles on the agar surface (Lo \& Dranginis, 1998). In turn, the extent of filament formation and invasive growth increases as FLO11 expression increases (Palecek et al., 2000). Increasing FLO11 expression polarizes cell shape, suggesting that Flo11 normally participates in determining polarity and morphology in addition to its role in adhesion and flocculation (Palecek et al., 2000). Perhaps Flo11 serves a signalling function as well, feeding back to enhance cell elongation. Fig2, an adhesin required for mating, can partially substitute for Flo11-mediated adhesion when overexpressed in a FLO11 mutant strain (Guo et al., 2000), suggesting some redundancy among flocculins. FLO11 is highly regulated, containing several repression and activation sequences in its promoter (Rupp et al., 1999). Ste12 and Tec1 regulate transcription from the MAPK cascade downstream of Kss1 while Flo8 regulates Flo11 transcription downstream of PKA (Madhani et al., 1999).

A lack of mother-daughter separation following cytokinesis may provide an alternative to cell-cell adhesion during filament formation. In pseudohyphal filaments, a complete septum is formed between mother and daughter cells at cytokinesis but it persists rather than being cleaved, maintaining a stable connection (Kron et al., 1994). In the vegetative cell cycle, the Ace2 and Swi5 transcription factors induce the endochitinase Cts1 and 
Table 2. Bud site selection

\begin{tabular}{|c|c|c|}
\hline Gene name & Protein function & Role in invasion (mutant phenotype) \\
\hline ACT1 & Structural protein & Involved in cell polarity \\
\hline AXL1 & Protease; hydrolase & $\begin{array}{l}\text { Required for axial budding pattern; required for cell fusion during } \\
\text { mating; mutant haploids invade }\end{array}$ \\
\hline BEM1 & Unknown - localizes to bud tip & Required for polarized apical growth \\
\hline BNI1 & $\begin{array}{l}\text { Unknown - localizes to bud tip } \\
\text { and bud neck }\end{array}$ & $\begin{array}{l}\text { Required for polarized apical growth and bipolar budding pattern in } \\
\text { diploids }\end{array}$ \\
\hline BUD1/RSR1 & GTP-binding protein/GTPase & $\begin{array}{l}\text { Required for bud site selection in both haploids and diploids; haploid and } \\
\text { diploid mutants display random bud site selection; diploid mutants } \\
\text { defective for pseudohyphal growth }\end{array}$ \\
\hline BUD2 & GAP & $\begin{array}{l}\text { Required for bud site selection in both haploids and diploids; haploid and } \\
\text { diploid mutants display random bud site selection }\end{array}$ \\
\hline BUD3 & Bud site marker & $\begin{array}{l}\text { Required for bud site selection in haploids; mutants bud at distal site and } \\
\text { invade agar }\end{array}$ \\
\hline BUD4 & Bud site marker & $\begin{array}{l}\text { Required for bud site selection in haploids; mutants bud at distal site and } \\
\text { invade agar }\end{array}$ \\
\hline BUD5 & GEF & $\begin{array}{l}\text { Required for bud site selection in both haploids and diploids; haploid and } \\
\text { diploid mutants display random bud site selection }\end{array}$ \\
\hline BUD6 & Unknown - localizes to bud neck & $\begin{array}{l}\text { Required for bud site selection and polarized apical growth; diploid } \\
\text { mutants display random bud site selection }\end{array}$ \\
\hline BUD8 & Bud site marker & $\begin{array}{l}\text { Required for polar bud site selection in diploids; mutants bud at proximal } \\
\text { pole and are noninvasive }\end{array}$ \\
\hline BUD9 & Bud site marker & $\begin{array}{l}\text { Required for bipolar bud site selection in diploids; mutants bud at distal } \\
\text { pole }\end{array}$ \\
\hline BUD10 & Unknown - localizes to bud site & Required for bud site selection in haploids \\
\hline CDC3 & Structural protein (septin) & $\begin{array}{l}\text { Required for axial budding pattern in haploids; required for normal } \\
\text { subcellular localization of Bni4p, Chs } 3 p \text { and Chs4p }\end{array}$ \\
\hline CDC10 & $\begin{array}{l}\text { GTP-binding } \\
\text { protein/GTPase; structural protein }\end{array}$ & $\begin{array}{l}\text { Required for axial budding pattern in haploids; required for normal } \\
\text { subcellular localization of Bni4p, Chs } 3 p \text { and Chs } 4 p\end{array}$ \\
\hline CDC11 & Structural protein (septin) & $\begin{array}{l}\text { Required for axial budding pattern in haploids; required for normal } \\
\text { subcellular localization of Bni4p, Chs } 3 p \text { and Chs } 4 p\end{array}$ \\
\hline CDC12 & Structural protein (septin) & $\begin{array}{l}\text { Required for axial budding pattern in haploids; required for normal } \\
\text { subcellular localization of Bni4p, Chs3p and Chs4p }\end{array}$ \\
\hline CDC24 & GEF & Required for budding and polarized apical growth \\
\hline
\end{tabular}

putative endoglucanase regulator Egt2 to cleave the septum in $\mathrm{G}_{1}$ (Dohrmann et al., 1996; Kovacech et al., 1996). Mutating CTS1 or ACE2 induces invasive filamentous growth, even in a floss background (King \& Butler, 1998). Similarly, mutations in EGT2 enhance pseudohyphal growth in a flo11s strain (Pan \& Heitman, 2000). Coupling septal maturation to cell adhesion, Swi5 regulates FLO11 transcription as well, most likely via the transcription factor ASH1 (Pan \& Heitman, 2000).

\section{Bud site selection}

Haploid bud site selection is predominantly axial (proximal), with each new bud emerging adjacent to the birth scar that forms after cleavage of the septum at the mother-daughter neck. Table 2 lists genes that induce axial, polar or random bud site selection. Axial budding cells use a marker at the site of cytokinesis to direct assembly of budding components at the new bud site. These markers may include Bud3, Bud4, Bud10, Axl1 and the septins Cdc3, Cdc10, Cdc11 and Cdc12 (Madden \& Snyder, 1998). Each of these proteins is necessary for proper axial bud site selection; deletion or mutations bias haploid cells toward distal pole budding but have no effect on bud site selection in diploids. In addition, cell wall synthesis proteins Kre9 and Hkr1 are involved in axial bud site selection (Brown \& Bussey, 1993; Yabe et al., 1996). Deletion of these proteins results in random budding. Pmt4, a protein mannosyl transferase that participates in O-linked glycosylation of secreted proteins, is also required for axial budding, probably via modification of Bud10 (Sanders et al., 1999). Diploid cells normally undergo bipolar budding in which buds emerge somewhat stochastically either adjacent or opposite to the birth scar (reviewed by Chant, 1999; Madden \& Snyder, 1998). A large group of proteins that are needed for bipolar budding has also been identified (e.g. Ni \& Snyder, 2001). Cytoskeletal and cytoskeleton binding proteins are required for bipolar budding in diploids. Mutations in actin depolarize budding in mother cells but have no effect on daughter cell bud site 
selection (Yang et al., 1997). Similar budding defects occur when actin-binding proteins Bni1, Rvs167, Sac6 (fimbrin), Sla2, Srv2 and Tpm1 (tropomyosin) or actinorganizing proteins Sla1 and Rvs161 are mutated (Madden \& Snyder, 1998; Mosch \& Fink, 1997; Yang et al., 1997). Another class of proteins required for both axial and distal bud site selection constitute a GTPase module. Rsr1 is the GTPase, Bud2 the GTPase-activating protein (GAP) and Bud5 the guanine nucleotide exchange factor (GEF) and together the complex directs bud assembly and growth at the proper location. Mutation in any component of this module causes random budding in both haploids and diploids and moderately inhibits invasive and filamentous growth (Madden \& Snyder, 1998; Taheri et al., 2000). In addition, Rsr1 interacts with the Cdc42 Rac/Rho-type GTPase, its GEF Cdc24 and Bem1, and is thought to direct polarized growth to the tags marking the appropriate bud site.

In diploid pseudohyphal growth in response to nitrogen starvation, bud site selection becomes skewed to a unipolar distal pattern where each new bud emerges from the pole opposite the birth scar (Gimeno et al., 1992; Kron et al., 1994). Mutations in genes required for bipolar budding in diploids such as BUD1, BUD5 or BUD8 prevent filament formation (Gimeno et al., 1992; Lo et al., 1997; Mosch \& Fink, 1997). BUD8 mutations switch diploid cells from bipolar bud site selection to proximal pole budding while mutations in BUD9 favour distal bud site selection (Zahner et al., 1996). Both Bud8 and Bud9 localize to the distal pole, suggesting that Bud8 serves as an initiator for distal bud site assembly while Bud9 is an inhibitor (Taheri et al., 2000). Some mutations in ACT1 also repress cell elongation and filamentous differentiation in response to low nitrogen (Cali et al., 1998). Also, mutations in the actin-binding proteins Tpm1, Sac6, Srv2 and Bni1 prevent filament formation (Mosch \& Fink, 1997). Tpm1 and Bni1 mutants can still invade agar, suggesting that the actin cytoskeleton controls physical processes regulating filamentation but does not affect invasive growth. Deletion of MYO3 and MYO5, genes encoding myosin I proteins, also prevent cell elongation and polarized bud site selection (Goodson et al., 1996). Other genes important in distal pole bud site selection include Spa2, Pea2 and Bud6/Aip3, which form a complex that localizes to budding and growth sites. Spa2 interacts with Ste11 and Ste7 while Bud6 binds Ste11 and actin, suggesting that the Spa2-Pea2-Bud6 complex may link filamentous growth signalling through the MAPK cascade to bud site selection. Deleting SPA2, $P E A 2$ or BUD6 increases random bud site selection in mother cells, depolarizes cell surface expansion and reduces cell elongation (Sheu et al., 2000; Zahner et al., 1996). Cdc42 and its effector Gic2 are required for localization of Spa2 and Bud6 to bud sites (Jaquenoud \& Peter, 2000). Spa2 and Sph1 may also be involved in localizing MAPK signalling during pseudohyphal growth. SPH1 and SPA2 double deletion cells cannot invade or form filaments (Roemer et al., 1998). Sph1 interacts with Ste7 and Ste11, suggesting that the polarization effects of these proteins may be due to localized MAPK signalling; however, it is unclear whether sph1 spa2 mutant phenotypes are due to signalling or physical defects, or both.

Polarized budding can promote haploid invasive growth provided a sufficient level of cell-cell adhesion exists. Mutations in BUD3, BUD4, BUD10 and AXL1 switch haploids to a polar budding pattern and turn on invasive growth independent of induction of Flo11, but they have no effect on filamentous growth in diploids (Palecek et al., 2000).

\section{Cell shape and polarity}

Although cell attachment and bud site selection are sufficient for growth in chains, the full pseudohyphal phenotype also encompasses an elongation of the usual ovoid cell morphology. This regulation of cell shape is coupled to cell cycle progression. Buds emerge late during the $G_{1}$ phase of the cell cycle. Initially, buds grow apically with new material added at the bud tip. Eventually, growth becomes isotropic with material added throughout the bud. This switch between apical and isotropic growth affects cell shape and filament formation (reviewed by Pruyne \& Bretscher, 2000). Disproportionate apical growth causes elongated cells while extended isotropic growth results in round cells. Molecular regulation of the cell cycle controls the switch between apical and isotropic growth, enhancing pseudohyphal differentiation via cell morphology. Table 3 summarizes genes involved in morphology regulation via the cell cycle. In general, Cln cyclins are polarizing while $\mathrm{Clb}$ cyclins are depolarizing. Overexpression of $\mathrm{Cln} 1$ or $\mathrm{Cln} 2$ promotes filamentous growth while deletion of $G_{1}$ cyclins $C \ln 1$ and $C \ln 2$ causes a severe defect in elongation and filamentation (Loeb et al., 1999; Madhani et al., 1999). Mutations in GRR1 or CDC53 may enhance apical growth, cell elongation and invasive growth in part by stabilizing $\mathrm{G}_{1}$ cyclins. In contrast, deletion of the $G_{2}$ cyclin $\mathrm{Clb} 2$ enhances polarized growth and bud site selection while overexpression of CLB2 suppresses elongation due to the ectopically activated MAPK pathway by reducing the $\mathrm{G}_{2} / \mathrm{M}$ delay in the cell cycle (Ahn et al., 1999; Edgington et al., 1999).

Septin mutations also enhance apical growth and bud elongation due to a $G_{2}$ delay (Longtine et al., 2000). Improper septin assembly in the bud neck appears to activate the Swe1 kinase by inactivating Elm1, Hsl1 and Hsl7. Swe1 then phosphorylates Cdc28, inactivating the $\mathrm{Clb}-\mathrm{Cdc} 28$ complex and delaying cell cycle progression. Analogous to the bud morphogenesis checkpoint, which limits mitosis unless a bud has formed, this pathway may represent a feedback circuit that restricts mitosis until a proper cytokinetic apparatus can be assembled. Mutations in ELM1, HSL1 or HSL7, overexpression of SWE1, or deletion of the antagonistic phosphatase 
Table 3. Cell morphology

\begin{tabular}{|c|c|c|}
\hline $\begin{array}{l}\text { Gene } \\
\text { name }\end{array}$ & Protein function & Role in invasion (mutant phenotype) \\
\hline CDC53 & Structural protein & $\begin{array}{l}\text { Inhibits apical growth; targets degradation of proteins, including } G_{1} \text { cyclins; } \\
\text { haploid mutants elongated, bud at proximal site and invade agar }\end{array}$ \\
\hline$C L B 2$ & $\mathrm{G}_{2}$ cyclin & $\begin{array}{l}\text { Depolarizes actin; inhibits polarized growth and elongation; mutants display } \\
\text { increased invasive and filamentous growth }\end{array}$ \\
\hline CLN1 & $\mathrm{G}_{1}$ cyclin & $\begin{array}{l}\text { Required for initiation of DNA replication and for bud emergence; enhances apical } \\
\text { growth and cell elongation; major } G_{1} \text { cyclin involved in filamentous growth; } \\
\text { mutants defective in invasive and filamentous growth }\end{array}$ \\
\hline CLN2 & $\mathrm{G}_{1}$ cyclin & $\begin{array}{l}\text { Required for initiation of DNA replication and for bud emergence; enhances apical } \\
\text { growth and cell elongation; mutants defective in invasive and filamentous growth }\end{array}$ \\
\hline ELM1 & Protein kinase & $\begin{array}{l}\text { Regulates Swe1; controls bud growth during mitosis; regulates Clb2-Cdc28; } \\
\text { mutants invade agar and display enhanced filamentous growth }\end{array}$ \\
\hline GRR1 & Complex assembly protein & $\begin{array}{l}\text { Inhibits apical growth; targets degradation of proteins, including } G_{1} \text { cyclins; } \\
\text { haploid mutants elongated, bud at proximal site and invade agar }\end{array}$ \\
\hline HSL1 & Protein kinase & $\begin{array}{l}\text { Inhibits Swe1; involved in transmitting nutritional information to Cdc28; involved } \\
\text { in switching from polarized to isotropic bud growth; inhibits cell elongation and } \\
\text { filamentous growth; mutants invade agar and display enhanced filamentous } \\
\text { growth }\end{array}$ \\
\hline HSL7 & Repressor & $\begin{array}{l}\text { Inhibits Swe1; inhibits cell elongation, polarized bud emergence and filamentous } \\
\text { growth; mutants invade agar and display enhanced filamentous growth }\end{array}$ \\
\hline SWE1 & Protein kinase & $\begin{array}{l}\text { Required for apical growth; inhibits Cdc } 28 \text { and mitosis; mutants defective for } \\
\text { filamentous growth }\end{array}$ \\
\hline
\end{tabular}

MIH1 all enhance elongation, polar bud site selection, filament formation and invasive growth via Swe1dependent tyrosine phosphorylation and inactivation of Cdc28 (Ahn et al., 1999; Bouquin et al., 2000; Edgington et al., 1999; Palecek et al., 2000).

\section{Other physical effects}

Yeast-matrix interactions other than adhesion may also enable invasive or filamentous growth. The MAPK Kss1 regulates expression of $P G U 1$, an enzyme that degrades polygalacturonic acid (Madhani et al., 1999). Perhaps other matrix-degrading enzymes are also regulated by filamentous growth signalling pathways. Furthermore, cell wall composition may affect yeast-matrix interactions. Mutations in DFG16 decrease invasive growth but do not affect cell morphology or polarity (Mosch \& Fink, 1997). These $d f g 16$ strains exhibit an increased ratio of mannose to glucose in their cell wall and a decreased sensitivity to the cell-surface-perturbing chemical calcofluor white.

\section{Conclusions and perspectives}

Pseudohyphal development in S. cerevisiae appears to be more complex than a simple differentiation switch. The process integrates signals from several nutrients and metabolic byproducts to construct a physical response that alters the adhesion, budding polarity, morphology and cell cycle control of individual cells in order to organize them into a structured network. Signals travel through two major pathways, cAMP-PKA and MAPK cascades, and elicit several distinct yet coregulated transcriptional responses that eventually affect how cells interact with each other and their environment.

Studies of filamentous and invasive growth of $S$. cerevisiae have also provided insight into the dimorphism of other fungal organisms, including pathogenic fungi and organisms used in biochemical processes (reviewed by Borges-Walmsley \& Walmsley, 2000; Brown \& Gow, 1999; Lengeler et al., 2000). While the stimuli inducing filamentation in the different organisms are likely to be quite distinct, the signalling pathways and physical responses seem to be well conserved. In addition, the transition from yeast form to hyphal or pseudohyphal growth is linked to virulence in a number of pathogenic fungi. For example, in the animal pathogen C. albicans, a serum factor initiates hyphal growth in a Ras1-dependent manner (Feng et al., 1999). The MAPK and PKA pathways also transmit filamentation signals in $C$. albicans. Deletion of the transcription factors Cph1 and Efg1, effectors of the MAPK- and PKA-signalling pathways, respectively, partly eliminates filamentation and reduces virulence in mice (Brown \& Gow, 1999; Lo et al., 1997).

Filament formation and virulence in the plant pathogen $U$. maydis also require the cAMP-PKA and MAPK pathways. However, in U. maydis, cAMP switches filamentous cells to a yeast-form phenotype, opposite of the effect seen in S. cerevisiae (Kronstad et al., 1998). Likewise, activation of PKA suppresses filament forma- 
tion and virulence (Durrenberger et al., 1998). Disruption of the MAPK pathway by mutating the MAPKKK UBC4, MAPKK UBC5 or MAPK UBC3 disrupts filament formation and pathogenicity, suggesting that the MAPK pathway stimulates filamentous growth in U. maydis (Andrews et al., 2000).

S. cerevisiae provides a genetically suitable organism for studying dimorphism of fungal organisms. Pathways and processes identified and characterized in S. cerevisiae will no doubt advance our understanding of analogous regulation of morphogenesis and pathogenicity in other organisms. In addition, this information may greatly facilitate the design of strains optimized for biochemical processing. Major challenges still remain in determining how cells sense filamentous growth signals from their environment, how various signalling cascades process and integrate filamentous growth signals, and how these signals manifest in physical processes leading to filament formation. Specifically, crucial challenges in the coming years from the sensory standpoint are to identify what metabolites cells sense and the receptors for these metabolites. At the signalling level, new strategies to identify nonlinear complexities in signal transduction, such as crosstalk and feedback loops, must be developed. Finally, an integrated model of how cell attachment, shape and budding polarity are regulated by these signalling pathways will lead to a better understanding of filamentous and invasive growth.

\section{Acknowledgements}

The authors thank their colleagues in the Kron and Palecek laboratories for helpful input and careful reading of the manuscript. S.P.P. was an Amgen Fellow of the Life Sciences Research Foundation and S. J. K. was a James S. McDonnell Foundation Scholar. Our studies have been supported by National Science Foundation grant MCB-9875976 to S. J.K.

\section{References}

Ahn, S. H., Acurio, A. \& Kron, S. J. (1999). Regulation of G2/M progression by the STE mitogen-activated protein kinase pathway in budding yeast filamentous growth. Mol Biol Cell 10, 33013316.

Andrews, D. L., Egan, J. D., Mayorga, M. E. \& Gold, S. E. (2000). The Ustilago maydis ubc4 and ubc5 genes encode members of a MAP kinase cascade required for filamentous growth. Mol Plant-Microbe Interact 13, 781-786.

Ansari, K., Martin, S., Farkasovsky, M., Ehbrecht, I. M. \& Kuntzel, H. (1999). Phospholipase C binds to the receptor-like GPR1 protein and controls pseudohyphal differentiation in Saccharomyces cerevisiae. J Biol Chem 274, 30052-30058.

Bardwell, L., Cook, J. G., Zhu-Shimoni, J. X., Voora, D. \& Thorner, J. (1998). Differential regulation of transcription: repression by unactivated mitogen-activated protein kinase Kss1 requires the Dig1 and Dig2 proteins. Proc Natl Acad Sci USA 95, 15400-15405.

Bennett, J. W. (1998). Mycotechnology: the role of fungi in biotechnology. J Biotechnol 66, 101-107.

Borges-Walmsley, M. I. \& Walmsley, A. R. (2000). cAMP sig- nalling in pathogenic fungi: control of dimorphic switching and pathogenicity. Trends Microbiol 8, 133-141.

Bothast, R. J., Nichols, N. N. \& Dien, B. S. (1999). Fermentations with new recombinant organisms. Biotechnol Prog 15, 867-875.

Bouquin, N., Barral, Y., Courbeyrette, R., Blondel, M., Snyder, M. \& Mann, C. (2000). Regulation of cytokinesis by the Elm1 protein kinase in Saccharomyces cerevisiae. J Cell Sci 113, 1435-1445.

Brown, A. J. \& Gow, N. A. (1999). Regulatory networks controlling Candida albicans morphogenesis. Trends Microbiol 7, 333-338.

Brown, J. L. \& Bussey, H. (1993). The yeast KRE9 gene encodes an O glycoprotein involved in cell surface beta-glucan assembly. Mol Cell Biol 13, 6346-6356.

Cali, B. M., Doyle, T. C., Botstein, D. \& Fink, G. R. (1998). Multiple functions for actin during filamentous growth of Saccharomyces cerevisiae. Mol Biol Cell 9, 1873-1889.

Carlson, M. (1999). Glucose repression in yeast. Curr Opin Microbiol 2, 202-207.

Chandarlapaty, S. \& Errede, B. (1998). Ash1, a daughter cellspecific protein, is required for pseudohyphal growth of Saccharomyces cerevisiae. Mol Cell Biol 18, 2884-2891.

Chant, J. (1999). Cell polarity in yeast. Annu Rev Cell Dev Biol 15, 365-391.

Chartrain, M., Salmon, P. M., Robinson, D. K. \& Buckland, B. C. (2000). Metabolic engineering and directed evolution for the production of pharmaceuticals. Curr Opin Biotechnol 11, 209214.

Christensen, B. \& Nielsen, J. (2000). Metabolic network analysis. A powerful tool in metabolic engineering. Adv Biochem Eng Biotechnol 66, 209-231.

Conlan, R. S. \& Tzamarias, D. (2001). Sfl1 functions via the corepressor Ssn6-Tup1 and the cAMP-dependent protein kinase Tpk2. J Mol Biol 309, 1007-1015.

Conte, D., Jr \& Curcio, M. J. (2000). Fus3 controls Ty1 transpositional dormancy through the invasive growth MAPK pathway. Mol Microbiol 35, 415-427.

Cook, J. G., Bardwell, L. \& Thorner, J. (1997). Inhibitory and activating functions for MAPK Kss1 in the $S$. cerevisiae filamentous-growth signalling pathway. Nature 390, 85-88.

Cullen, P. J. \& Sprague, G. F., Jr (2000). Glucose depletion causes haploid invasive growth in yeast. Proc Natl Acad Sci U S A 97, 13619-13624.

Cullen, P. J., Schultz, J., Horecka, J., Stevenson, B. J., Jigami, Y. \& Sprague, G. F., Jr (2000). Defects in protein glycosylation cause SHO1-dependent activation of a STE12 signaling pathway in yeast. Genetics 155, 1005-1018.

Dohrmann, P. R., Voth, W. P. \& Stillman, D. J. (1996). Role of negative regulation in promoter specificity of the homologous transcriptional activators Ace2p and Swi5p. Mol Cell Biol 16, 1746-1758.

Donzeau, M. \& Bandlow, W. (1999). The yeast trimeric guanine nucleotide-binding protein alpha subunit, Gpa2p, controls the meiosis-specific kinase Ime2p activity in response to nutrients. Mol Cell Biol 19, 6110-6119.

D'Souza, C. A. \& Heitman, J. (2001). Conserved cAMP signaling cascades regulate fungal development and virulence. FEMS Microbiol Rev 25, 349-364.

Durrenberger, F., Wong, K. \& Kronstad, J. W. (1998). Identification of a cAMP-dependent protein kinase catalytic subunit required for virulence and morphogenesis in Ustilago maydis. Proc Natl Acad Sci U S A 95, 5684-5689. 
Edgington, N. P., Blacketer, M. J., Bierwagen, T. A. \& Myers, A. M. (1999). Control of Saccharomyces cerevisiae filamentous growth by cyclin-dependent kinase Cdc28. Mol Cell Biol 19, 1369-1380.

Edskes, H. K., Hanover, J. A. \& Wickner, R. B. (1999). Mks1p is a regulator of nitrogen catabolism upstream of Ure2p in $\mathrm{Sac}$ charomyces cerevisiae. Genetics 153, 585-594.

Erdman, S., Lin, L., Malczynski, M. \& Snyder, M. (1998). Pheromone-regulated genes required for yeast mating differentiation. J Cell Biol 140, 461-483.

Feng, Q., Summers, E., Guo, B. \& Fink, G. (1999). Ras signaling is required for serum-induced hyphal differentiation in Candida albicans. J Bacteriol 181, 6339-6346.

Fujita, A., Tonouchi, A., Hiroko, T., Inose, F., Nagashima, T., Satoh, R. \& Tanaka, S. (1999). Hsl7p, a negative regulator of Ste20p protein kinase in the Saccharomyces cerevisiae filamentous growth-signaling pathway. Proc Natl Acad Sci USA 96, $8522-8527$.

Gagiano, M., van Dyk, D., Bauer, F. F., Lambrechts, M. G. \& Pretorius, I. S. (1999). Msn1p/Mss10p, Mss11p and Muc1p/ Flo11p are part of a signal transduction pathway downstream of Mep2p regulating invasive growth and pseudohyphal differentiation in Saccharomyces cerevisiae. Mol Microbiol 31, 103-116.

Galitski, T., Saldanha, A. J., Styles, C. A., Lander, E. S. \& Fink, G. R. (1999). Ploidy regulation of gene expression. Science 285, 251-254.

Gancedo, J. M. (1998). Yeast carbon catabolite repression. Microbiol Mol Biol Rev 62, 334-361.

Gancedo, J. M. (2001). Control of pseudohyphae formation in Saccharomyces cerevisiae. FEMS Microbiol Rev 25, 107-123.

Gavrias, V., Andrianopoulos, A., Gimeno, C. J. \& Timberlake, W. E. (1996). Saccharomyces cerevisiae TEC1 is required for pseudohyphal growth. Mol Microbiol 19, 1255-1263.

Gibbs, P. A., Seviour, R. J. \& Schmid, F. (2000). Growth of filamentous fungi in submerged culture: problems and possible solutions. Crit Rev Biotechnol 20, 17-48.

Gimeno, C. J. \& Fink, G. R. (1994). Induction of pseudohyphal growth by overexpression of PHD1, a Saccharomyces cerevisiae gene related to transcriptional regulators of fungal development. Mol Cell Biol 14, 2100-2112.

Gimeno, C. J., Ljungdahl, P. O., Styles, C. A. \& Fink, G. R. (1992). Unipolar cell divisions in the yeast $S$. cerevisiae lead to filamentous growth: regulation by starvation and RAS. Cell 68, 1077-1090.

Goodson, H. V., Anderson, B. L., Warrick, H. M., Pon, L. A. \& Spudich, J. A. (1996). Synthetic lethality screen identifies a novel yeast myosin I gene (MYO5): myosin I proteins are required for polarization of the actin cytoskeleton. J Cell Biol 133, 1277-1291.

Guo, B., Styles, C. A., Feng, Q. \& Fink, G. R. (2000). A Saccharomyces gene family involved in invasive growth, cell-cell adhesion, and mating. Proc Natl Acad Sci U S A 97, 12158-12163.

Hammond, J. R. (1995). Genetically-modified brewing yeasts for the 21st century. Progress to date. Yeast 11, 1613-1627.

Hollenhorst, P. C., Bose, M. E., Mielke, M. R., Muller, U. \& Fox, C. A. (2000). Forkhead genes in transcriptional silencing, cell morphology and the cell cycle. Overlapping and distinct functions for FKH1 and FKH2 in Saccharomyces cerevisiae. Genetics 154, 1533-1548.

Jansen, G., Buhring, F., Hollenberg, C. P. \& Ramezani Rad, M. (2001). Mutations in the SAM domain of STE50 differentially influence the MAPK-mediated pathways for mating, filamentous growth and osmotolerance in Saccharomyces cerevisiae. Mol Genet Genomics 265, 102-117.
Jaquenoud, M. \& Peter, M. (2000). Gic2p may link activated Cdc42p to components involved in actin polarization, including Bni1p and Bud6p (Aip3p). Mol Cell Biol 20, 6244-6258.

Khale, A. \& Deshpande, M. V. (1992). Dimorphism in Benjaminiella poitrasii: cell wall chemistry of parent and two stable yeast mutants. Antonie Leeuwenhoek 62, 299-307.

Khazak, V., Sadhale, P. P., Woychik, N. A., Brent, R. \& Golemis, E. A. (1995). Human RNA polymerase II subunit hsRPB7 functions in yeast and influences stress survival and cell morphology. Mol Biol Cell 6, 759-775.

King, L. \& Butler, G. (1998). Ace2p, a regulator of CTS1 (chitinase) expression, affects pseudohyphal production in Saccharomyces cerevisiae. Curr Genet 34, 183-191.

Klasson, H., Fink, G. R. \& Ljungdahl, P. O. (1999). Ssy1p and Ptr3p are plasma membrane components of a yeast system that senses extracellular amino acids. Mol Cell Biol 19, 5405-5416.

Kleyn, J. \& Hough, J. (1971). The microbiology of brewing. Annu Rev Microbiol 25, 583-608.

Kobayashi, O., Yoshimoto, H. \& Sone, H. (1999). Analysis of the genes activated by the FLO8 gene in Saccharomyces cerevisiae. Curr Genet 36, 256-261.

Kovacech, B., Nasmyth, K. \& Schuster, T. (1996). EGT2 gene transcription is induced predominantly by Swi5 in early G1. Mol Cell Biol 16, 3264-3274.

Kron, S. J. \& Gow, N. A. (1995). Budding yeast morphogenesis: signalling, cytoskeleton and cell cycle. Curr Opin Cell Biol 7, 845-855.

Kron, S. J., Styles, C. A. \& Fink, G. R. (1994). Symmetric cell division in pseudohyphae of the yeast Saccharomyces cerevisiae. Mol Biol Cell 5, 1003-1022.

Kronstad, J., De Maria, A. D., Funnell, D., Laidlaw, R. D., Lee, N., de Sa, M. M. \& Ramesh, M. (1998). Signaling via cAMP in fungi: interconnections with mitogen-activated protein kinase pathways. Arch Microbiol 170, 395-404.

Kubler, E., Mosch, H. U., Rupp, S. \& Lisanti, M. P. (1997). Gpa2p, a G-protein alpha-subunit, regulates growth and pseudohyphal development in Saccharomyces cerevisiae via a cAMP-dependent mechanism. J Biol Chem 272, 20321-20323.

Lambrechts, M. G., Bauer, F. F., Marmur, J. \& Pretorius, I. S. (1996). Muc1, a mucin-like protein that is regulated by Mss10, is critical for pseudohyphal differentiation in yeast. Proc Natl Acad Sci U S A 93, 8419-8424.

Lee, B. N. \& Elion, E. A. (1999). The MAPKKK Ste11 regulates vegetative growth through a kinase cascade of shared signaling components. Proc Natl Acad Sci US A 96, 12679-12684.

Lengeler, K. B., Davidson, R. C., D'Souza, C., Harashima, T., Shen, W. C., Wang, P., Pan, X., Waugh, M. \& Heitman, J. (2000). Signal transduction cascades regulating fungal development and virulence. Microbiol Mol Biol Rev 64, 746-785.

Li, W. \& Mitchell, A. P. (1997). Proteolytic activation of Rim1p, a positive regulator of yeast sporulation and invasive growth. Genetics 145, 63-73.

Liu, H., Styles, C. A. \& Fink, G. R. (1996). Saccharomyces cerevisiae S288C has a mutation in FLO8, a gene required for filamentous growth. Genetics 144, 967-978.

Lo, H. J., Kohler, J. R., DiDomenico, B., Loebenberg, D., Cacciapuoti, A. \& Fink, G. R. (1997). Nonfilamentous C. albicans mutants are avirulent. Cell 90, 939-949.

Lo, W. S. \& Dranginis, A. M. (1998). The cell surface flocculin Flo11 is required for pseudohyphae formation and invasion by Saccharomyces cerevisiae. Mol Biol Cell 9, 161-171. 
Loeb, J. D., Kerentseva, T. A., Pan, T., Sepulveda-Becerra, M. \& Liu, H. (1999). Saccharomyces cerevisiae G1 cyclins are differentially involved in invasive and pseudohyphal growth independent of the filamentation mitogen-activated protein kinase pathway. Genetics 153, 1535-1546.

Longtine, M. S., Theesfeld, C. L., McMillan, J. N., Weaver, E., Pringle, J. R. \& Lew, D. J. (2000). Septin-dependent assembly of a cell cycle-regulatory module in Saccharomyces cerevisiae. Mol Cell Biol 20, 4049-4061.

Lorenz, M. C. \& Heitman, J. (1997). Yeast pseudohyphal growth is regulated by GPA2, a $\mathrm{G}$ protein alpha homolog. EMBO J 16, 7008-7018.

Lorenz, M. C. \& Heitman, J. (1998a). Regulators of pseudohyphal differentiation in Saccharomyces cerevisiae identified through multicopy suppressor analysis in ammonium permease mutant strains. Genetics 150, 1443-1457.

Lorenz, M. C. \& Heitman, J. (1998b). The MEP2 ammonium permease regulates pseudohyphal differentiation in Saccharomyces cerevisiae. EMBO J 17, 1236-1247.

Lorenz, M. C., Cutler, N. S. \& Heitman, J. (2000a). Characterization of alcohol-induced filamentous growth in Saccharomyces cerevisiae. Mol Biol Cell 11, 183-199.

Lorenz, M. C., Pan, X., Harashima, T., Cardenas, M. E., Xue, Y., Hirsch, J. P. \& Heitman, J. (2000b). The G protein-coupled receptor gpr1 is a nutrient sensor that regulates pseudohyphal differentiation in Saccharomyces cerevisiae. Genetics 154, 609-622.

Madden, K. \& Snyder, M. (1998). Cell polarity and morphogenesis in budding yeast. Annu Rev Microbiol 52, 687-744.

Madhani, H. D., Styles, C. A. \& Fink, G. R. (1997). MAP kinases with distinct inhibitory functions impart signaling specificity during yeast differentiation. Cell 91, 673-684.

Madhani, H. D., Galitski, T., Lander, E. S. \& Fink, G. R. (1999). Effectors of a developmental mitogen-activated protein kinase cascade revealed by expression signatures of signaling mutants. Proc Natl Acad Sci U S A 96, 12530-12535.

Miled, C., Mann, C. \& Faye, G. (2001). Xbp1-mediated repression of $C L B$ gene expression contributes to the modifications of yeast cell morphology and cell cycle seen during nitrogen-limited growth. Mol Cell Biol 21, 3714-3724.

Morillon, A., Springer, M. \& Lesage, P. (2000). Activation of the Kss1 invasive-filamentous growth pathway induces Ty1 transcription and retrotransposition in Saccharomyces cerevisiae. Mol Cell Biol 20, 5766-5776.

Moriya, H., Shimizu-Yoshida, Y., Omori, A., Iwashita, S., Katoh, M. \& Sakai, A. (2001). Yak1p, a DYRK family kinase, translocates to the nucleus and phosphorylates yeast Pop2p in response to a glucose signal. Genes Dev 15, 1217-1228.

Mosch, H. U. \& Fink, G. R. (1997). Dissection of filamentous growth by transposon mutagenesis in Saccharomyces cerevisiae. Genetics 145, 671-684.

Mosch, H. U., Roberts, R. L. \& Fink, G. R. (1996). Ras2 signals via the Cdc42/Ste20/mitogen-activated protein kinase module to induce filamentous growth in Saccharomyces cerevisiae. Proc Natl Acad Sci U S A 93, 5352-5356.

Mosch, H. U., Kubler, E., Krappmann, S., Fink, G. R. \& Braus, G. H. (1999). Crosstalk between the Ras2p-controlled mitogen-activated protein kinase and cAMP pathways during invasive growth of Saccharomyces cerevisiae. Mol Biol Cell 10, 1325-1335.

Mosch, H. U., Kohler, T. \& Braus, G. H. (2001). Different domains of the essential GTPase Cdc42p required for growth and development of Saccharomyces cerevisiae. Mol Cell Biol 21, 235-248.
Murray, L. E., Rowley, N., Dawes, I. W., Johnston, G. C. \& Singer, R. A. (1998). A yeast glutamine tRNA signals nitrogen status for regulation of dimorphic growth and sporulation. Proc Natl Acad Sci U S A 95, 8619-8624.

Ni, L. \& Snyder, M. (2001). A genomic study of the bipolar bud site selection pattern in Saccharomyces cerevisiae. Mol Biol Cell 12, 2147-2170.

Oehlen, L. J. \& Cross, F. R. (1998). Potential regulation of Ste20 function by the Cln1-Cdc28 and Cln2-Cdc28 cyclin-dependent protein kinases. J Biol Chem 273, 25089-25097.

O'Rourke, S. M. \& Herskowitz, I. (1998). The Hog1 MAPK prevents cross talk between the HOG and pheromone response MAPK pathways in Saccharomyces cerevisiae. Genes Dev 12, 2874-2886.

Ostergaard, S., Olsson, L. \& Nielsen, J. (2000). Metabolic engineering of Saccharomyces cerevisiae. Microbiol Mol Biol Rev 64, 34-50.

Palecek, S. P., Parikh, A. S. \& Kron, S. J. (2000). Genetic analysis reveals that FLO11 upregulation and cell polarization independently regulate invasive growth in Saccharomyces cerevisiae. Genetics 156, 1005-1023.

Pan, X. \& Heitman, J. (1999). Cyclic AMP-dependent protein kinase regulates pseudohyphal differentiation in Saccharomyces cerevisiae. Mol Cell Biol 19, 4874-4887.

Pan, X. \& Heitman, J. (2000). Sok2 regulates yeast pseudohyphal differentiation via a transcription factor cascade that regulates cell-cell adhesion. Mol Cell Biol 20, 8364-8372.

Pan, X., Harashima, T. \& Heitman, J. (2000). Signal transduction cascades regulating pseudohyphal differentiation of Saccharomyces cerevisiae. Curr Opin Microbiol 3, 567-572.

Peter, M., Neiman, A. M., Park, H. O., van Lohuizen, M. \& Herskowitz, I. (1996). Functional analysis of the interaction between the small GTP binding protein Cdc42 and the Ste20 protein kinase in yeast. EMBO J 15, 7046-7059.

Posas, F., Takekawa, M. \& Saito, H. (1998). Signal transduction by MAP kinase cascades in budding yeast. Curr Opin Microbiol 1, 175-182.

Pretorius, I. S. (2000). Tailoring wine yeast for the new millennium: novel approaches to the ancient art of winemaking. Yeast 16, 675-729.

Pruyne, D. \& Bretscher, A. (2000). Polarization of cell growth in yeast. J Cell Sci 113, 571-585.

Radcliffe, P. A., Binley, K. M., Trevethick, J., Hall, M. \& Sudbery, P. E. (1997). Filamentous growth of the budding yeast Saccharomyces cerevisiae induced by overexpression of the WHI2 gene. Microbiology 143, 1867-1876.

Roberts, R. L., Mosch, H. U. \& Fink, G. R. (1997). 14-3-3 proteins are essential for RAS/MAPK cascade signaling during pseudohyphal development in S. cerevisiae. Cell 89, 1055-1065.

Robertson, L. S. \& Fink, G. R. (1998). The three yeast A kinases have specific signaling functions in pseudohyphal growth. Proc Natl Acad Sci U S A 95, 13783-13787.

Robertson, L. S., Causton, H. C., Young, R. A. \& Fink, G. R. (2000). The yeast A kinases differentially regulate iron uptake and respiratory function. Proc Natl Acad Sci U S A 97, 5984-5988.

Roemer, T., Vallier, L., Sheu, Y. J. \& Snyder, M. (1998). The Spa2related protein, $S p h 1 p$, is important for polarized growth in yeast. J Cell Sci 111, 479-494.

Rolland, F., De Winde, J. H., Lemaire, K., Boles, E., Thevelein, J. M. \& Winderickx, J. (2000). Glucose-induced cAMP signalling in yeast requires both a G-protein coupled receptor system for 
extracellular glucose detection and a separable hexose kinasedependent sensing process. Mol Microbiol 38, 348-358.

Rupp, S., Summers, E., Lo, H. J., Madhani, H. \& Fink, G. (1999). MAP kinase and cAMP filamentation signaling pathways converge on the unusually large promoter of the yeast FLO11 gene. EMBO J 18, 1257-1269.

Russell, M., Bradshaw-Rouse, J., Markwardt, D. \& Heideman, W. (1993). Changes in gene expression in the Ras/adenylate cyclase system of Saccharomyces cerevisiae: correlation with cAMP levels and growth arrest. Mol Biol Cell 4, 757-765.

Sabbagh, W., Flatauer, L. J., Bardwell, A. J. \& Bardwell, L. (2001). Specificity of MAP kinase signaling in yeast differentiation involves transient versus sustained MAPK activation. Mol Cell 8, 683-691.

San-Blas, G. (1993). Biochemical and physiological aspects in the dimorphism of Paracoccidioides brasiliensis. Arch Med Res 24, 267-268.

San-Blas, G., Travassos, L. R., Fries, B. C. \& 10 other authors (2000). Fungal morphogenesis and virulence. Med Mycol 38 (suppl. 1), 79-86.

Sanchez-Martinez, C. \& Perez-Martin, J. (2001). Dimorphism in fungal pathogens: Candida albicans and Ustilago maydissimilar inputs, different outputs. Curr Opin Microbiol 4, 214-221.

Sanders, S. L., Gentzsch, M., Tanner, W. \& Herskowitz, I. (1999). O-Glycosylation of Axl2/Bud10p by Pmt4p is required for its stability, localization, and function in daughter cells. J Cell Biol 145, 1177-1188.

Schilling, C. H., Schuster, S., Palsson, B. O. \& Heinrich, R. (1999). Metabolic pathway analysis: basic concepts and scientific applications in the post-genomic era. Biotechnol Prog 15, 296-303.

Schroder, M., Chang, J. S. \& Kaufman, R. J. (2000). The unfolded protein response represses nitrogen-starvation induced developmental differentiation in yeast. Genes Dev 14, 2962-2975.

Sheu, Y. J., Barral, Y. \& Snyder, M. (2000). Polarized growth controls cell shape and bipolar bud site selection in Saccharomyces cerevisiae. Mol Cell Biol 20, 5235-5247.

Stanhill, A., Schick, N. \& Engelberg, D. (1999). The yeast ras/cyclic AMP pathway induces invasive growth by suppressing the cellular stress response. Mol Cell Biol 19, 7529-7538.

Straver, M. H., vd Aar, P. C., Smit, G. \& Kijne, J. W. (1993). Determinants of flocculence of brewer's yeast during fermentation in wort. Yeast 9, 527-532.

Taheri, N., Kohler, T., Braus, G. H. \& Mosch, H. U. (2000). Asymmetrically localized Bud8p and Bud9p proteins control yeast cell polarity and development. EMBO J 19, 6686-6696.

Tamaki, H., Miwa, T., Shinozaki, M., Saito, M., Yun, C. W., Yamamoto, K. \& Kumagai, H. (2000). GPR1 regulates filamentous growth through FLO11 in yeast Saccharomyces cerevisiae. Biochem Biophys Res Commun 267, 164-168.

Uren, A. G., Beilharz, T., O'Connell, M. J., Bugg, S. J., van Driel, R., Vaux, D. L. \& Lithgow, T. (1999). Role for yeast inhibitor of apoptosis (IAP)-like proteins in cell division. Proc Natl Acad Sci U S A 96, 10170-10175.

Viard, B. \& Kuriyama, H. (1997). Phase-specific protein expression in the dimorphic yeast Saccharomyces cerevisiae. Biochem Biophys Res Commun 233, 480-486.

Ward, M. P., Gimeno, C. J., Fink, G. R. \& Garrett, S. (1995). SOK2 may regulate cyclic AMP-dependent protein kinase-stimulated growth and pseudohyphal development by repressing transcription. Mol Cell Biol 15, 6854-6863.

Wartmann, T. \& Kunze, G. (2000). Genetic transformation and biotechnological application of the yeast Arxula adeninivorans. Appl Microbiol Biotechnol 54, 619-624.

Wilkinson, B. M., James, C. M. \& Walmsley, R. M. (1996). Partial deletion of the Saccharomyces cerevisiae GDH3 gene results in novel starvation phenotypes. Microbiology 142, 1667-1673.

Wright, R. M., Repine, T. \& Repine, J. E. (1993). Reversible pseudohyphal growth in haploid Saccharomyces cerevisiae is an aerobic process. Curr Genet 23, 388-391.

Xue, Y., Batlle, M. \& Hirsch, J. P. (1998). GPR1 encodes a putative $G$ protein-coupled receptor that associates with the Gpa2p Galpha subunit and functions in a Ras-independent pathway. EMBO J 17, 1996-2007.

Yabe, T., Yamada-Okabe, T., Kasahara, S., Furuichi, Y., Nakajima, T., Ichishima, E., Arisawa, M. \& Yamada-Okabe, H. (1996). HKR1 encodes a cell surface protein that regulates both cell wall betaglucan synthesis and budding pattern in the yeast Saccharomyces cerevisiae. J Bacteriol 178, 477-483.

Yang, S., Ayscough, K. R. \& Drubin, D. G. (1997). A role for the actin cytoskeleton of Saccharomyces cerevisiae in bipolar bud-site selection. J Cell Biol 136, 111-123.

Yun, C. W., Tamaki, H., Nakayama, R., Yamamoto, K. \& Kumagai, H. (1998). Gpr1p, a putative G-protein coupled receptor, regulates glucose-dependent cellular cAMP level in yeast Saccharomyces cerevisiae. Biochem Biophys Res Commun 252, 29-33.

Zahner, J. E., Harkins, H. A. \& Pringle, J. R. (1996). Genetic analysis of the bipolar pattern of bud site selection in the yeast Saccharomyces cerevisiae. Mol Cell Biol 16, 1857-1870.

Zhang, Z., Smith, M. M. \& Mymryk, J. S. (2001). Interaction of the E1A oncoprotein with Yak1p, a novel regulator of yeast pseudohyphal differentiation, and related mammalian kinases. Mol Biol Cell 12, 699-710.

Zhu, G., Spellman, P. T., Volpe, T., Brown, P. O., Botstein, D., Davis, T. N. \& Futcher, B. (2000). Two yeast forkhead genes regulate the cell cycle and pseudohyphal growth. Nature 406, 90-94. 